\title{
An historic overview of biological response modifiers as antiviral agents
}

Page S Morahan, PhD, Angelo J Pinto, PhD

\begin{abstract}
PS Morahan, AJ Pinto. An historic overview of biological response modifiers as antiviral agents. Can J Infect Dis 1992;3(Suppl B):34B-40B. A wide variety of immunomodulators/biological response modifiers (BRMs) has been demonstrated to provide broad spectrum antiviral activity against both RNA and DNA viruses in several animal species. Dramatic decreases in mortality, reduced virus titres in tissues and reduced histopathology can be produced. The antivirally effective agents include microbially derived materials, polyanions, cytokines and chemically diverse small molecular weight chemicals. The greatest protective effects are observed with prophylactic treatment, although early therapeutic treatment can also be effective. Little direct antiviral activity can be observed in vitro. The findings suggest induction by BRMs of antiviral mediators in vivo early in the course of viral pathogenesis, before the virus has become sequestered in a privileged site or too much infectious virus has been produced for natural resistance to have an impact. Immunomodulators are pleiotropic in their immunomodulatory effects, and it has been difficult to establish whether one cell type or mediator is critical for the observed broad spectrum antiviral activity. Therefore, the mechanisms of antiviral action of immunomodulators remain unclear for most systems, but probably involve enhancement of natural immune responses. While no unified antiviral mechanism among different immunomodulators has yet emerged, interferon induction remains a major hypothesis.
\end{abstract}

Key Words: Antivirals, Biological response modifiers, Immunomodulators, Interferon

\section{Historique des modificateurs de la réponse biologique utilisés à titre d'antiviraux}

RÉSUMÉ: L'on a démontré qu'une grande variété d'immuno-modulateurs/modificateurs de la réponse biologique (MRB) avaient une activité antivirale à large spectre, tant contre les virus à ARN qu'à ADN et ce, dans diverses espèces animales. Une reduction remarquable des taux de mortalité, des titres viraux tissulaires et des lesions pathologiques peut être induite par ces médicaments. Les agents efficaces contre les virus incluent les substances d'origine microbienne, polyanions, cytokines et diverses substances de faible poids moléculaire. Les effets protecteurs les plus importants s'observent dans le cas de traitements prophylactiques, bien que les traitments inities très tôt puissent également être efficaces. On observe peu d'activité antivirale directe in vitro. Les résultats suggèrent qu'un traitement d'induction avec des MRB des médiateurs antiviraux in vivo doit être appliqué au début du processus infectieux avant que le virus ne se soit logé dans un site privilégié ou que la réplication virale n'ait atteint un niveau tel que la résistance naturelle en soit affectée. Les immuno-modulateurs sont pléiotropiques dans leur imuno-modulation et il a été difficile d'établir si un seul type de cellules ou de médateurs est critique en ce qui a trait à l'activité antivirale à large spectre. Les mécanismes de l'action antivirale des immunomodulateurs demeurent donc imprécis pour la plupart des systèmes, mais supposent probablement une amêlioration des réponses immunitaires naturelles. Bien qu'aucun mécanisme commun expliquant l'activite antivirale des différents immuno-modulateurs ne se soit encore démarqué, l'hypothèse principale demeure l'induction des l'interféron. 
$\mathrm{T}$ HE CONCEPT FOR THE USE OF BIOLOGICAL RESPONSE modifiers (BRMs) to produce antiviral resistance began with the discovery in 1957 that viruses could induce interferons that exhibited broad spectrum antiviral activity in vivo and in vitro. Shortly thereafter came the discovery that substances other than viruses could stimulate the production of interferon. Since the mid 1960s, a variety of microbially derived substances and synthetic small molecular weight molecules or polymers have been documented to produce antiviral effects in experimental infections (1-5). Examples of BRMs with antiviral activity show a surprisingly diverse range of chemical structures (Table 1). Active compounds include microbially derived small and large molecular weight products from both Gram-negative and Gram-positive bacteria, as well as other microorganisms. The synthetically derived materials range from small molecular weight chemicals to large molecular weight polyanions and polysaccharides (2). The newest BRMs are proteins that are produced by recombinant DNA technology.

TABLE 1

Examples of immunomodulators with antiviral efficacy

\begin{tabular}{|c|c|c|}
\hline Name & Composition & Source \\
\hline \multicolumn{3}{|l|}{ Microbials } \\
\hline Cparvum & Killed bacterial vaccine & $\begin{array}{l}\text { Burroughs } \\
\text { Wellcome }\end{array}$ \\
\hline TDM & Trehalose dimycolate & Ribi Chem \\
\hline MPL & $\begin{array}{l}\text { Detoxified monophosphoryl } \\
\text { lipid A }\end{array}$ & Ribi Chem \\
\hline
\end{tabular}

Synthetics

7-Th-8-OxG 7-Thia 8-oxyguanosine

CL246,738 3,6-bis (2-piperidinoethoxy) acridine

Nucleic Acids Research

Lederle

MVE-2 Maleic anhydride divinyl ether Hercules copolymer

ABPP

2-NH2-5-Br-6-phenyl-4 (3H)

pyrimidinone

ABMP

2-NH2-5-Br-6-methyl-4 (3H) pyrimidinone

AIPP

2-NH2-5-1-6-phenyl-4 (3H)

pyrimidinone

Ampligen Mismatched poly rl:rC

PolyICLC Polyribonucleotide-lysine carboxymethylcellulose

Recombinant DNA derived

IMUIFN-G Murine gamma interferon

IHUIFNAAD Human alpha A/D interferon

IMulFN-B Murine beta interferon

Upjohn

Upjohn

Upjohn

Johns

Hopkins/HEM

$\mathrm{NCl}$

Genentech

Hoffmann-

La Roche

Toray Industries

HUTNF-A Human fumour necrosis factor Genentech alpha

rHuCSF-M Human macrophage colony stimulating factor

\section{DNA TECHNOLOGY}

Despite the marked antiviral effects, immunomodulation has yet to achieve its clinical potential. This is due in part to: the need to treat early; the toxicity of some BRMs; and finding both suppression and enhancement of viral disease in certain experimental systems $(6,7)$. With the development of early diagnostic capability, it may be possible to treat infections earlier than previously thought possible. Also there is continued development of less toxic synthetic immunomodulators with more narrow immunomodulatory effects (8), and the production of normal cytokines by recombinant DNA technology (5). Finally, immunomodulation, in combination with chemotherapeutic antimicrobial drugs, is being investigated in severe viral and other microbial infections in normal and immunocompromised hosts $(9,10)$. The combination of antivirals with different mechanisms of action may prove particularly useful in patients with acquired immune deficiency syndrome (AIDS), or those being treated with immunosuppressive regimens, such as renal transplant or cancer patients. Synergy has been demonstrated between poly ICLC or CL246,738 and ribavirin $(11,12)$, and between several nucleoside analogues and alpha-interferon (13-15) in several experimental models of viral infections.

This brief overview of BRMs as antivirals will focus primarily on major concepts that have been established in research conducted in the authors' laboratories over the past 20 years with the polyanionic immunomodulators. The reader is referred to the research cited in reviews 2,3 and 16 and to references 1,4 and 5 for the broad literature in this area.

\section{ANTIVIRAL ACTION}

It is unclear whether there is any common structure activity relationship among the diverse BRMs that is responsible for the antiviral activity. Even within a particular type of chemical, it has not yet been possible to establish all of the critical structural features. Significant antiviral activity of the carboxylic polyanions such as MVE-2 or pyran appears to be associated with such features as: a relatively high molecular weight (less than 10,000 Da); a dense appearance of negative charges; a relatively stable and therefore poorly biodegradable backbone; and specific chemical groupings and spatial configuration along the backbone (2). There is an obvious need for continued investigation into the exact chemical structures required for antiviral activity of BRMs, and determination of whether there are any common structural features involved.

The antiviral action of BRMs does exhibit similar features $(2,3)$. First, the antiviral activity is nonspecific and is expressed in many animal species; marked protection can be provided against both RNA and DNA viruses. For example, treatment of mice, hamsters, guinea pigs, pigs or rabbits with the pyran or MVE-2 
TABLE 2

\section{Prophylactic and therapeutic antiviral effects of BRMs}

\begin{tabular}{|c|c|c|c|c|c|c|c|c|}
\hline \multirow[b]{2}{*}{ Drug } & \multicolumn{2}{|c|}{ HSV-2 } & \multicolumn{2}{|c|}{ BV } & \multicolumn{2}{|c|}{ SFV } & \multicolumn{2}{|c|}{$\mathrm{CV}$} \\
\hline & $\begin{array}{l}\mathrm{P} \text { or } \\
\mathrm{P} / \mathrm{T}\end{array}$ & $\mathrm{T}$ & $\begin{array}{l}\mathrm{P} \text { or } \\
\mathrm{P} / \mathrm{T}\end{array}$ & $\mathrm{T}$ & $\begin{array}{l}\mathrm{P} \text { or } \\
\mathrm{P} / \mathrm{T}\end{array}$ & $\mathbf{T}$ & $\begin{array}{l}\mathrm{P} \text { or } \\
\mathrm{P} / \mathrm{T}\end{array}$ & $\mathrm{T}$ \\
\hline Cparvum & ++ & & ++ & & ++ & & ++ & \\
\hline MVE-2 & ++ & - & ++ & & ++ & & ++ & \\
\hline CL246,738 & ++ & ++ & ++ & + & ++ & & + & + \\
\hline Ampligen & ++ & ++ & ++ & + & ++ & + & + & - \\
\hline Poly ICLC & & & & + & & + & ++ & \\
\hline rMuIFN-G & ++ & ++ & & - & ++ & + & + & + \\
\hline rHuIFN-A & & & & & & & & \\
\hline$A / D$ & ++ & ++ & & + & ++ & ++ & + & $+1-$ \\
\hline rMuIFN-B & ++ & ++ & & + & ++ & + & - & - \\
\hline rHUCSF-M & - & & - & & - & & - & \\
\hline rHUTNF-A & - & & - & & & & + & \\
\hline ABPP & ++ & & ++ & + & ++ & & - & \\
\hline AIPP & ++ & & ++ & & ++ & & - & \\
\hline ABMP & - & & $+1-$ & - & ++ & & - & \\
\hline
\end{tabular}

Summary of data in references 4 and 5. BV Banzi virus; CV Caraparu virus HSV-2 Herpes simplex virus type 2; SFV Semliki Forest virus; P Single prophylactic and/or repeated prophylactic and therapeutic treatment; $T$ Repeated therapeutic treatment. ++ Significant reduction in mortality and increase in median survival time; + Significant increase in median survival time only; $+1-$ Inconsistent protection

type of polyanions has produced protection against lethality or tumour production by viruses in RNA virus families (picorna-, rhabdo-, orthomyxo-, alphatoga-, flavi-, retroviruses) and DNA virus families (herpes-, adeno-, papova-, poxviruses) (1-5).

Second, the antiviral activity of BRMs appears to be mediated indirectly, through effects on the host, because: the compounds do not inhibit viral replication in vitro at the concentrations that are effective in vivo; there is much greater efficacy of antiviral action with prophylactic treatment than with therapeutic treatment; and BRM treatment can provide systemic protection as well as local protection against viral infection. The duration of the prophylactic efficacy of immunomodulators can be striking; protection can be observed as long as three to four weeks after single treatment with an immunomodulator (6). Although prophylaxis is generally more effective, early therapeutic administration can prove equally effective (Table 2) $(4,5,17)$, which leads to the possibility of using immunomodulators in clinical infections.

Third, the antiviral activity of BRMs is expressed very early in the course of viral pathogenesis (3). Evidence for this includes: early inhibition of viral replication in tissues; low viral specific humoral- or cell-mediated immune responses in BRM-protected mice; lack of virus-specific resistance in BRM-treated survivors; and antiviral activity in immunosuppressed mice, eg, mice that are splenectomized, depleted of T cells, or treated with cyclophosphamide.

All of these features are consistent with the concept that the activity of BRMs is mediated indirectly through
TABLE 3

Pleotropic immunomodulatory effects of regimens of BRM administration that provide antiviral efficacy

Peritoneal macrophage activation

\begin{tabular}{lccccccc} 
Compound & NK & IFN & $5^{\prime} \mathrm{N}$ & APD & AT & Int & Ext \\
\hline Placebo & - & - & - & - & - & + & - \\
Cparvum & - & $+/-$ & + & + & + & + & + \\
MVE-2 & - & $+1-$ & + & + & + & + & + \\
CL246,738 & + & + & + & + & + & + & + \\
Ampligen & + & + & + & + & + & + & + \\
rMulFN-G & + & + & + & + & + & + & + \\
rHuIFN-A A/D & + & + & $+1-$ & $+/-$ & $+/-$ & + & +
\end{tabular}

5N 5 'nucleotidase; APD Alkaline phosphodiesterase: AT Antitumour; IFN Plasma interferon induction: NK Splenic natural killer cell activity. Ectoenzyme specific activity phenotype where ++ and + indicate a significant decrease in specific activity compared with control macrophages and $+/$-indicates inconsistent protection. Int Intrinsic antiviral activity where + indicates a nonpermissiveness for virus growth within the macrophage. Ext Extrinsic antiviral activity where + indicates macrophage-mediated inhibition of virus growth in permissive cells

induction of nonspecific host responses that lead to inhibition of viral growth or spread early in viral pathogenesis before specific immune responses are gener ated. The question that remains to be addressed is whether there is a common nonspecific host resistance mechanism that is induced by chemically distinct BRMs, a mechanism that is effective against viruses with diverse replication strategies and pathogenesis patterns.

\section{MECHANISMS OF ACTION}

Most BRMs that exhibit antiviral activity have also been shown to be pleiotropic immunomodulators that exert widespread effects on nonspecific and specific immune responses (Table 3$)(2,4,16,18)$. Reported ef fects include: activation of macrophages; activation o natural killer cells; enhancement of antibody production to various antigens and vaccines, immunoregula tion of cell-mediated immune responses; induction o interferon and other cytokines; and alteration of the complement and coagulation systems. In addition to these effects on immune responses, BRMs have direct or indirect effects on brain functions, such as increas ing slow wave sleep, eliciting fever or increasing noradrenaline metabolism (19). This multitude o physiological effects on the host has made it difficult to establish whether there is one essential, unified mechanism of antiviral activity. It is clear that diverse chemicals can produce the similar result of protection against viral infections, but this protection has not yet been correlated with modulation of any common hos immune response.

There are several possible explanations for the ap parent absence of a common mechanism (4). First there may be no common mechanism of action. Im munomodulator-induced resistance to one virus may 
TABLE 4

Protective antiviral efficacy in biological response modifiers in immunosuppressed mice

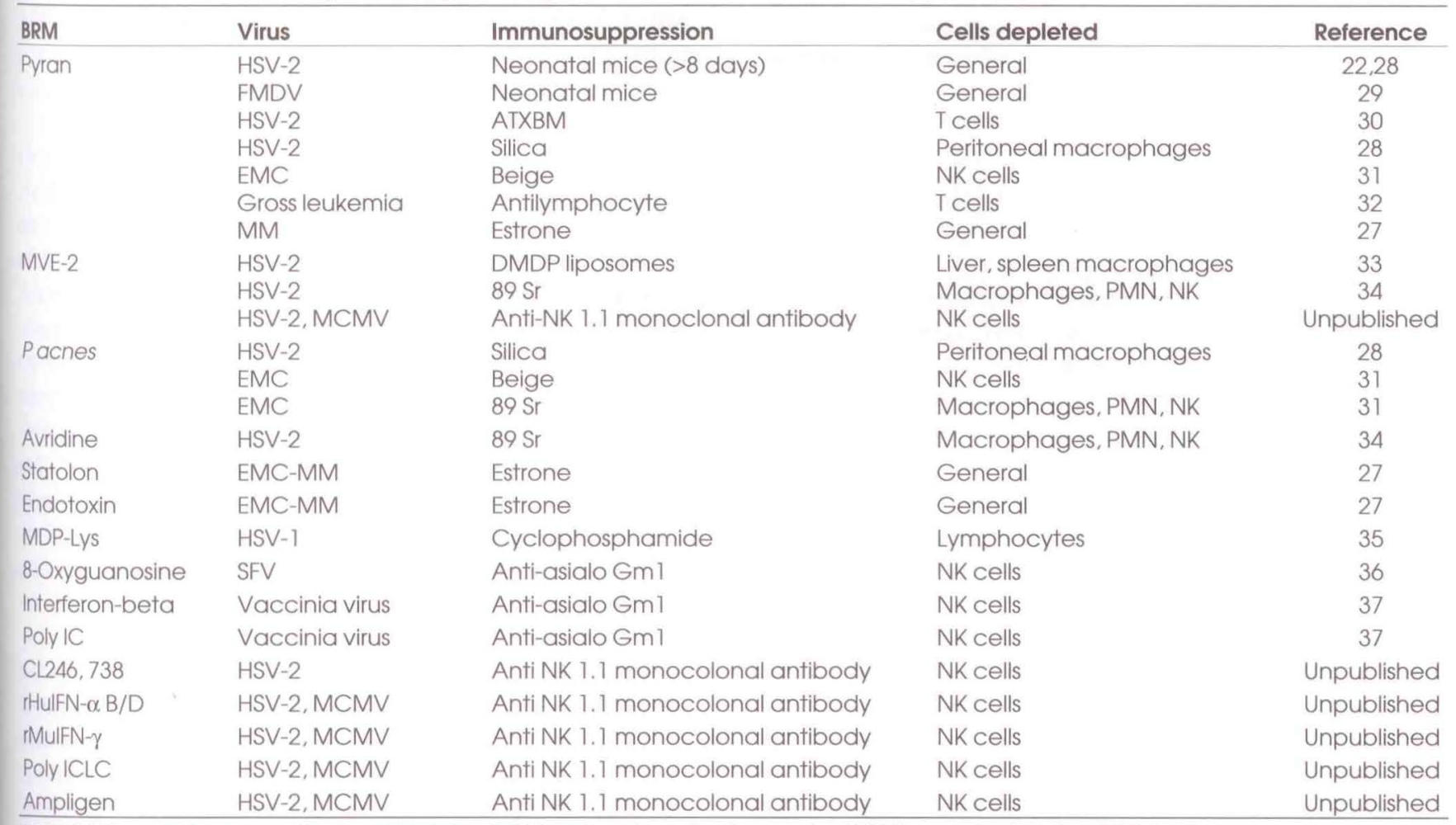

EMC-MM Encephalomyocarditis virus MM strain; FMDV Foot-and-mouth disease virus; HSV Herpes simplex virus; MCMV Murine cytomegalovirus; NK Natural killer: PMN Polymorphonucleocytes;SFV Semliki Forest virus

involve a unique combination of antiviral defence mechanisms that depends upon the virus replication strategy, route of infection, pattern of pathogenesis and host genetic factors that affect the magnitude of resistance mechanisms such as natural killer cell activity and interferon production. Second, a common antiviral mechanism may exist, but at sites or cells other than those that are commonly examined. Establishment of this hypothesis will require studies of the kinetics of host responses to be performed using the particular target organs for viral replication and histopathology rather than using blood, peritoneal compartment or spleen (sites often measured in the mouse). Measurements are also needed to assess changes in the cells in the context of the tissue (eg, immunofluorescence, image analysis, in situ hybridization or polymerase chain reaction) rather than on tissue homogenates or isolated cells in vitro. Third, activation of host responses such as natural killer cells or macrophages, as assessed by the assays commonly used (antitumour assays), may not be a true index of the antiviral activity of these cell populations. Methods need to be developed for the direct measurement of extrinsic and intrinsic cellular antiviral activity (18).

Two experimental approaches have proven very useful in delineating specific immune responses to microbial infections. These are measurement of the effects on viral pathogenesis that accompany the transfer of spec- ific T or B lymphocyte effector cells or the converse approach, selective depletion of these lymphocytes or their subsets. For example, the use of the nude mouse, which is genetically deficient in the thymus and thus in $\mathrm{T}$ lymphocytes, was pivotal in establishing the role of $\mathrm{T}$ lymphocytes in host resistance to a variety of microorganisms.

There has been limited use of the selective transfer or depletion experimental approaches in establishing the mechanism of antiviral action of immunomodulators. Part of the difficulty stems from inability to transfer sufficient numbers of purified cells, the lack of recipient models which are selectively lacking in the cells which are to be transferred and the lack of sufficiently selective cell depletion methods for nonspecific effector cells such as macrophages (20).

The limited studies on transfer of immunomodulator-activated cells have focused on macrophages. There have been no reports of the effects of transfer of immunomodulator-activated natural killer cells on viral infections. The studies with macrophages have shown that transfer of $10^{7}$ peritoneal cells (about a mouse equivalent) from adult mice treated with pyran, protected mice against Friend leukemia virus (21). Immunomodulator-activated cells were required because transfer of $1 \mathrm{~mL}$ of serum from pyran-treated mice, or $10^{7}$ glycogen-elicited inflammatory peritoneal cells, was ineffective. Similar transfer of pyran-activated perito- 
TABLE 5

Role of interferon in immunomodulator antiviral action

\begin{tabular}{lcccc}
\hline BRM & Virus & $\begin{array}{c}\text { IFN anti- } \\
\text { body }\end{array}$ & $\begin{array}{c}\text { Antiviral } \\
\text { efficacy }\end{array}$ & Reference \\
\hline 8-oxy & Alpha/beta & Lost & 36 \\
guanosine & SFV & Alphast & 40 \\
CL246.738 & SFV & Alpha & Lost & 39 \\
& SFV & Beta & Lost & 39 \\
& SFV & Alpha/beta & Lost & 40 \\
ABMP & SFV & Alpha/beta & Lost & Unpublished \\
Poly IC & Banzi & Alpha/beta & Lost & Undished \\
& Banzi & Beta & Mainained Unpublished & 39 \\
Ampligen & SFV & Alpha/beta & Partially lost & 39 \\
MVE-2 & SFV & Alpha/beta & Partially lost & 39 \\
Poly ICLC & SFV & Alpha/beta & Maintained & 39 \\
\hline
\end{tabular}

IFN Interferon; SFV Semliki Forest virus

neal cells into sucking mice, but not prophylactic treatment with pyran alone, protected mice against subsequent infection with herpes simplex virus type $2(22)$. Transfer of Corynebacterium acnes-activated peritoneal cells into adult mice has also been shown to protect mice against herpes simplex virus infection (23).

These early studies have clearly established the protective abilities of immunomodulator-activated peritoneal cells, but cannot prove that these cells are the essential antiviral mechanism in immunomodulatorprotected animals. Now that there is more information available on the heterogeneity of mononuclear phagocytes (24), it would be helpful to transfer more highly purified and stable, labelled cell populations $(25,26)$, and to follow the effects on viral pathogenesis using the molecular virology techniques now available.

There have been numerous studies documenting the antiviral efficacy of immunomodulators in mice suppressed of various cell populations (Table 4). In some cases, even though natural resistance was severely depressed, immunomodulator treatment gave complete protection $(27,33,34)$. In other situations, immunomodulator treatment was effective when measured against an infection burden in the immunosuppressed animal that was equivalent to that in the immunocompetent controls $(27,30)$. Efficacy of BRMs against herpes simplex virus, cytomegalovirus or foot-and-mouth disease virus infections has been demonstrated in naturally immunodeficient states, such as that observed in neonatal mice $(28,29,38)$ or beige mice congenitally deficient in natural killer cell function (31). The effectiveness of the streptococcal preparation OK432 or the protein-bound polysaccharide PS-K against murine cytomegalovirus was lost when mice were treated with anti-asialo GM1 serum (38). However, efficacy of numerous other immunomodulators has been demonstrated to be maintained in various experimentally induced immunocompromised states, such as animals: rendered deficient in T cell responses $(30,32)$; treated with immunosuppressive agents such as cyclophosphamide (35); treated with ${ }^{89} \mathrm{Sr}$ to cause deficiency in circulating monocytes, granulocytes and natural killer cells $(31,34)$; treated with anti-asialo GM1 antibody to natural killer cells $(36,37$, unpublished data); or treated with silica or other agents known to affect tissue macrophages $(28,33)$.

These observations of significant antiviral activity in the face of profound immunosuppression suggest that, in general, no single cell population studied appears to be essential for BRM-induced antiviral activity. This interpretation must be qualified, however, by the inability to eliminate completely most of the cell types investigated. For example, it is as yet impossible to eliminate all mononuclear phagocytes, including those in the bone marrow, peripheral blood and in the tissues. Moreover, if antiviral activity is mediated by soluble substances produced by certain cells, only small numbers of cells at critical sites may be necessary. In this case, it is questionable whether the cells producing the essential antiviral mediators could be sufficiently depleted to show their role.

The soluble antiviral mediators that have received the most attention for providing a possible unified mechanism of BRM-induced antiviral activity are the interferons. An interferon-mediated mechanism would be consistent with the common features of BRMinduced antiviral activity: viral nonspecificity, greater activity with prophylaxis than with therapeutic ad ministration and early effects in viral pathogenesis. Early observations, however, suggested that interferon were not the common antiviral mechanism of all BRMs $(2,3)$. There was a lack of correlation of ability of a given BRM to induce circulating interferon and to elicit antiviral activity $(3,39)$, a lack of correlation of kinetics of interferon induction with duration of antiviral protec tion (6), equal antiviral efficacy with doses of BRMs tha induced or did not induce circulating interferon (39), lack of abrogation of antiviral efficacy with treatment of animals with anti-interferon serum $(2,3)$ and lack of antiviral efficacy with transfer of serum (21).

More recent investigations, using higher titred antiinterferon sera, have suggested that interferon may be essential for the antiviral efficacy of at least some immunomodulators (Table 5). Sarzotti et al (40) reported that treatment of mice with anti-alpha or with anti-beta-interferon antibodies abrogated the antivira efficacy produced by prophylactic CL246,738 treatmen against Semliki forest virus infection. They concluded that alpha- and beta-interferon were independently required for antiviral activity of this BRM. The present authors have recently confirmed the importance of alpha- and beta-interferon for this immunomodulator using a high titred sheep antiserum against alpha- and beta-interferon (39).

Alpha- and beta-interferon induction also appeared to be essential for the prophylactic antiviral activity of the ABMP pyrimidinone (39) or 7-thia-8-oxyguanosine 
(36) against Semliki forest virus infection. Antiviral efficacy of the polyribonucleotide poly IC against Banzi virus infection appeared to require induction of alphainterferon because treatment of mice with antiserum against alpha- and beta-interferon, but not with antiserum against beta-interferon, abrogated protection (personal communication).

Thus, antiviral efficacy of at least four synthetic immunomodulators of diverse chemical structure (ABMP pyrimidinone, CL246,738, 7-thia-8-oxyguanosine, poly IC) appears to require either or both alphaand beta-interferons when measured against two arboviruses that are sensitive to interferon in vitro. Questions that remain are whether alpha- or beta-interferon is the critical antiviral mediator, what cells produce the interferon and whether interferon induction by these immunomodulators is their common mechanism of antiviral action against other viruses that vary in sensitivity to interferon and in pathogenesis.

Alpha- and beta-interferon also appear to be at least partially involved in the antiviral efficacy against Semliki forest virus infection of two other polyanionic immunomodulators, MVE-2 and the mismatched polyribonucleotide Ampligen (39). The data with MVE-2 are particularly intriguing, since the early observations with the more polydisperse parent material, pyran, indicated that interferon was probably not important $(2,3)$. Whether the results reflect differences in the

ACKNOWLEDGEMENTS: This work was partially supported by a grant from the National Institute of Allergy and Infectious Diseases (AI 25751), a contract from the Army (DMAD 17-866-6117) and a contract from the Office of Naval Research (ONR N00014-82-K-0069).

\section{REFERENCES}

1. Morahan PS, Leake ER, Tenney DJ, Sit M. Comparative analysis of modulators of nonspecific resistance against microbial infections. In: Majde J, ed. Immunopharmacology of Infectious Diseases: Vaccine Adjuvants and Modulators of Nonspecific Resistance. New York: Alan R Liss, 1987:313-24.

2. Morahan PS. Anionic polymers and polysaccharides: Overview of interferon inducing ability, antitumor activity and mechanisms of action. In: Hersh EM, Chirigos MA, Mastrangelo MJ, eds. Augmenting Agents in Cancer Therapy. New York: Raven Press, 1981:185-92.

3. Breinig MC, Morahan PS. Interferon inducers: Polyanions and others. In: Stringfellow DA, ed. Interferon and Interferon Inducers. New York: Marcel Dekker, 1980:239-61.

4. Pinto AJ, Morahan PS, Brinton MA. Comparative study of various immunomodulators for macrophage and natural killer cell activation and antiviral efficacy against exotic RNA viruses. Int $\mathrm{J}$ Immunopharm 1988:10:197-209.

5. Pinto AJ, Morahan PS, Brinton M, Stewart D, Gavin E. Comparative therapeutic efficacy of recombinant interferons alpha, beta and gamma against alphatogavirus, bunyavirus, flavivirus and herpesvirus infections. J Interf Res 1990:10:293-8. compounds or the potency and specificity of the antiinterferon antibody remain to be determined.

The antiviral efficacy against Semliki forest virus for at least one immunomodulator, poly ICLC, has not been able to be abrogated by treatment of mice with very high titres of anti-interferon antibody (39). Complete antiviral protection remained, even though induction of circulating interferon by poly ICLC was almost completely eliminated, and natural host resistance to the virus was markedly reduced.

Considering the selective cell depletion and mediator depletion data, there are several possibilities for the antiviral activities of poly ICLC, Ampligen and MVE-2: interferon may be induced at critical sites and consumed rapidly by local cells so that this interferon is not available to be neutralized by the antibody; small numbers of cells remaining after the various cell depletion methods may be all that are required to start the amplifying cascade of production of cytokines such as interferons that exert direct antiviral action; or cells that are not affected by the selective depletion method can function as direct or indirect (through induction of interferon or other cytokines) antiviral effector cells because of the pleiotropic activating effects of BRMs and the protective redundancy of the nonspecific immune system. Investigation of combinations of selective cell and mediator depletion methods may distinguish between these possible BRM-induced antiviral mechanisms.

6. Schuller GB, Morahan PS, Snodgrass M. Inhibition and enhancement of Friend leukemia virus by pyran copolymer. Cancer Res 1975:35:1915-20.

7. Warren RP, Morrey JD, Burger RA, Okleberry KM, Sidwell RW. Murine retroviral disease enhancing effects of a pyrimidinone immunomodulator. The Pharmacol 1989:31:166-9.

8. Barnes DW, Morahan PS, Loveless S, Munson AE. The effects of maleic anhydride divinyl ether (MVE) copolymers on hepatic microsomal mixed function oxidases and other biologic activities. J Pharm Exp Ther 1979:208:392-8.

9. Broxmeyer HE, Vadham R. Preclinical and clinical studies with the hematopoietic colony stimulating factors and related interleukins. Immunol Res 1989:8:185-201.

10. Sidwell RW, Huffman JH, Singh VK, et al. Use of the Punta Toro virus murine phlebovirus model for the evaluation of immunomodulating agents alone and in combination with antivirals. J Cell Biochem 1990:140:71-82.

11. Kende M, Lupton HW, Canonico PG. Treatment of experimental viral infections with immunomodulators. Adv Biosci 1988:68:51-63.

12. Kende M, Lupton HW, Rill WL, Levy HB, Canonico PG. Enhanced therapeutic efficacy of poly ICLC and ribavirin combinations against Rift valley fever virus infection of mice. Antimicrob Agents Chemother 1987:31:986-90.

13. Fraser-Smith EB, Eppstein DA, Marsh YV, Matthews TR. Enhanced efficacy of the acyclic nucleoside

9-(1,3-dihydroxy-2-propoxymethyl) guanine in combination with alpha interferon against herpes simplex virus type 2 in mice. Antimicrob Agents Chemother 1984:26:937-8. 


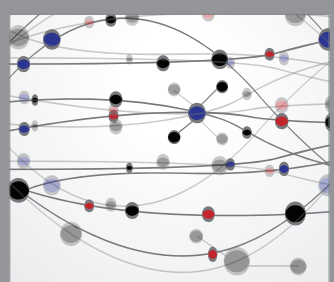

The Scientific World Journal
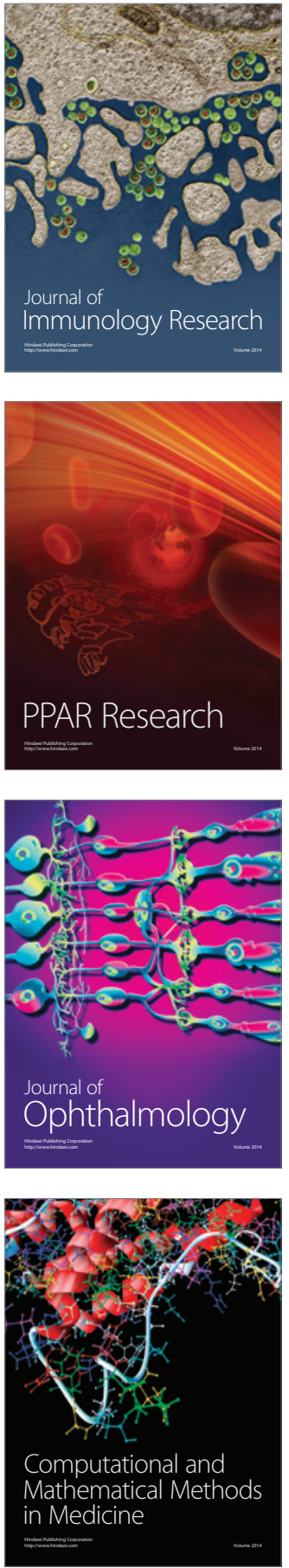

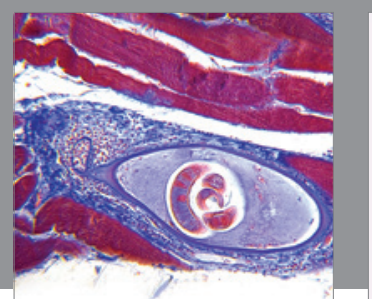

Gastroenterology Research and Practice

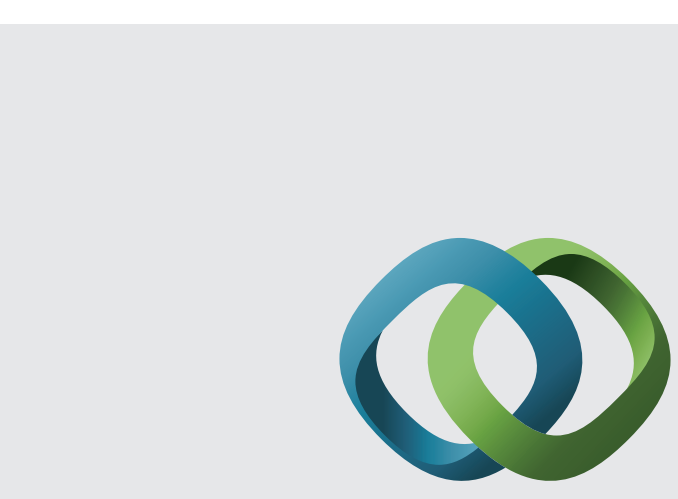

\section{Hindawi}

Submit your manuscripts at

http://www.hindawi.com
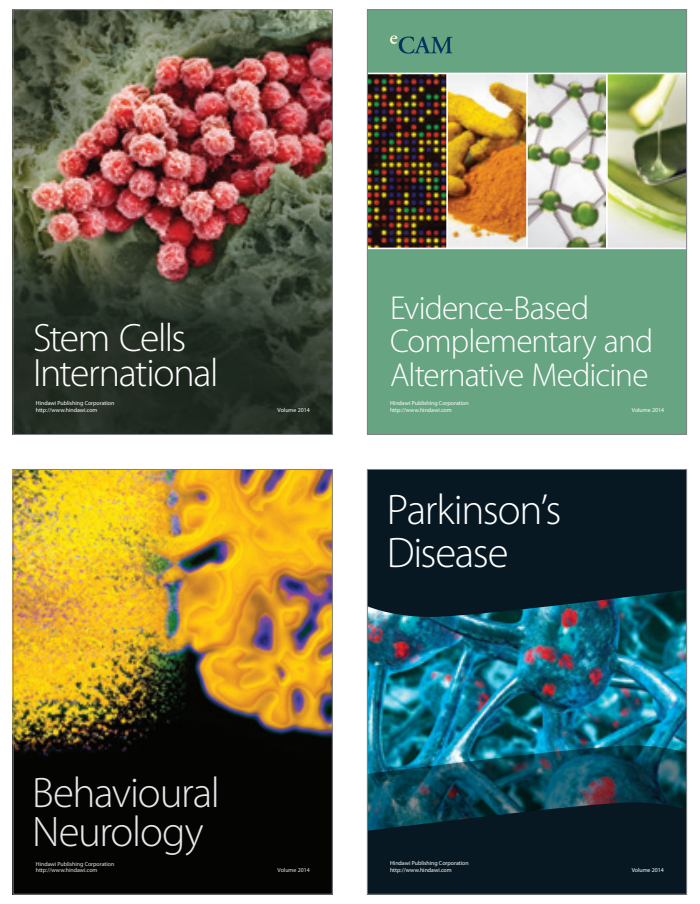
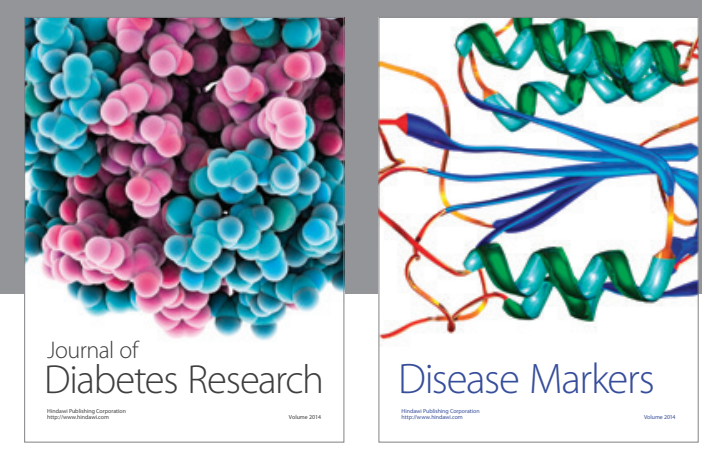

Disease Markers
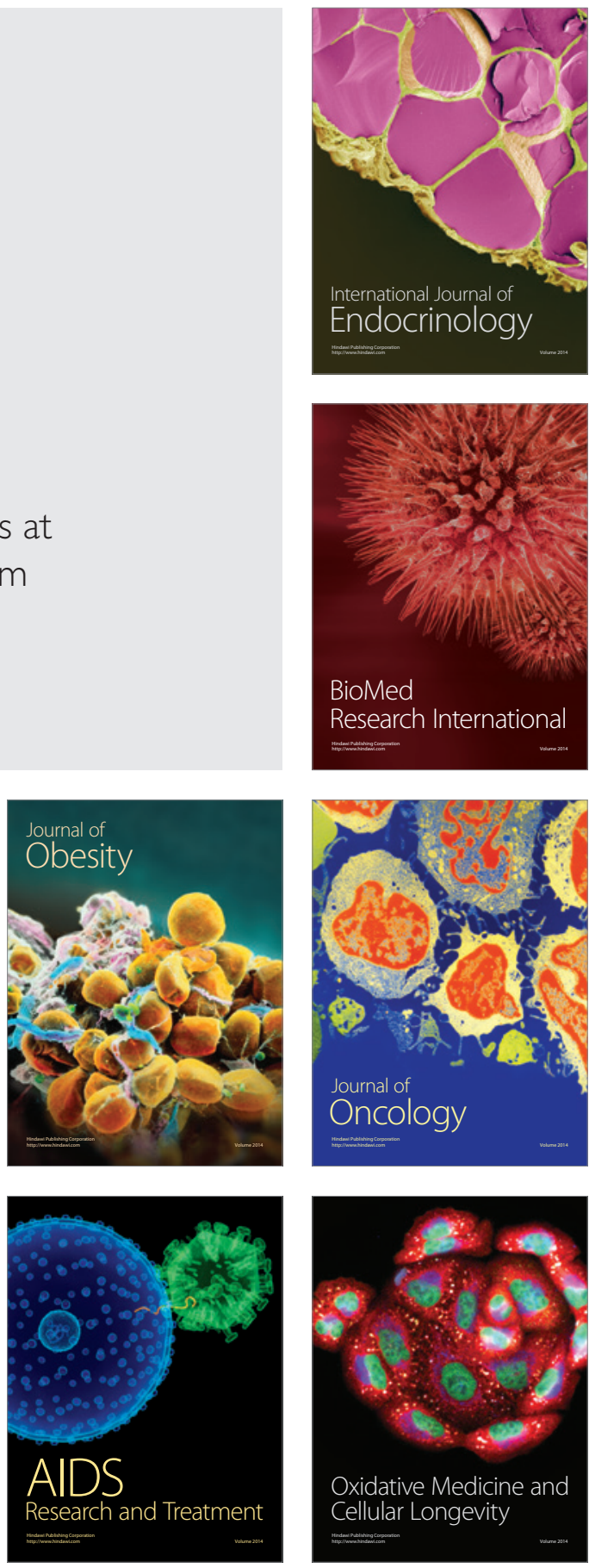